\title{
Review
}

\section{Assessing Panspermia Hypothesis by Microorganisms Collected from The High Altitude Atmosphere}

\author{
Yinjie Yang, Shin-ichi Yokobori \\ and Akihiko Yamagishi ${ }^{\dagger}$ \\ Department of Molecular Biology, Tokyo University \\ of Pharmacy and Life Science, 1432-1, Horinouchi, \\ Hachioji, Tokyo 192-0392, Japan
}

\begin{abstract}
Microbiology at the high altitude atmosphere is important for assessing the chances and limits of microbial transfer from the earth to extraterrestrial bodies. Among the microorganisms isolated from the highatmospheric samples, spore formers and vegetative Deinococci were highly resistant against harsh environment at high altitude. From limited knowledge available to date, it is suggested that terrestrial microorganisms may have had chances to be ejected and transferred to outer space. Survival of these organisms during their space travel and proliferation on other planets might be also feasible. Directed Panspermia from Earth to extraterrestrial bodies is discussed on the basis of findings reported in literatures. (c)2009 Jpn. Soc. Biol. Sci. Space; Article ID: 092303017
\end{abstract}

\section{Introduction}

Great attentions have been paid to the questions 'How did life on Earth originate?' and 'Is life on Earth alone in the universe?'. Many efforts have been made to answer to these questions. Abiogenesis (also known as spontaneous generation) hypotheses such as the Miller-Urey Experiment (Miller, 1953), protenoid (Fox, 1973), and the RNA World (Gilbert, 1986), have been proposed and widely discussed with many findings and observations. The panspermia hypothesis is another hypothesis for the origin of the life on Earth. The panspermia hypothesis was initially proposed by Arrhenius (1903). It argues that terrestrial life was seeded by the extraterrestrial life forms after traveling by radiation pressure (Weber and Greenberg, 1985) or meteorites (Melosh, 1988). Directed panspermia could be either from outer space to Earth (Crick and Orgel, 1973; Hoyle and Wickramasinghe, 1979) or from Earth to seed extraterrestrial bodies (Mautner and Matloff, 1979).

Received: June 22, 2009; Accepted: August 11, 2009

†To whom correspondence should be addressed: Tel.: +8142-676-7139; Fax: +81-42-676-7145;

E-mail: yamagish@ls.toyaku.ac.jp
Verification of the panspermia hypothesis had been difficult due to the limit of human ability to investigate the extraterrestrial space during the earlier years. However, in the past several decades, space technology has allowed us to deploy probes into outer space beyond Mars. Recent exploration of the polar region of Mars (Titus et al., 2003; Bandfield, 2007; Kerr, 2008) indicates that at least water, an essential requirement for life, existed on Mars. It should be noted that space probes may carry terrestrial microbes even strict sterilization procedures will be taken, and that some microbes may survive on extraterrestrial bodies through spacecraft crash on them (La Duc et al., 2004; McLean et al., 2006). There is a risk of spreading terrestrial microbes to the extraterrestrial world at conducting human activities. It is very likely that directed panspermia from Earth to other planets has been going on since the beginning of our space exploration.

Another means for terrestrial microbes to travel outer space are by natural carriers such as meteorites (Mileikowsky et al., 2000), dust, or even microbes alone. Such natural transfer could have been made since billions of years ago when microbes were widely distributed on Earth. Microbes could have reached other bodies in our solar system and even extrasolar systems. It is also possible that some of the transferred microbes remain alive or dormant on extraterrestrial bodies under favorable conditions for their preservation (Yang et al., 2009c).

Terrestrial microbes resulting from such transfer would pass through Earth's atmosphere before reaching outer space. The gravitational force decreases at higher altitude. Presumably, the higher the altitude that microbes can reach, the higher the possibility they escape into outer space. Except the input by human activities and rare events of large meterorite impact, a possible mechanism to steadily eject microbes from high altitude to outer space has been suggested. The forces of Earth's electric fileds on charged microbes at high altitudes are at times strong enought to counteract the gravatational force on the microbes and uplift them into near-earth space (Dehel, 2006). Also, the high altitude atmosphere (HAA) resembles outer space in some physical conditions (desiccation, low pressure, low temperature and high levels of radiation). Therefore, information on microbes in the HAA is important for assessing the chances and limits of directed panspermia of terrestrial life. Here we review microbiological studies in the HAA for providing valuable information on the panspermia hypothesis. Reviews on the microbes in the HAA associated with disease spread and cloud nuclei formation could be found elsewhere (Lundheim, 2002; Kellogg and Griffin, 2006; Griffin, 2007).

\section{Microbes in the HAA}

There is no common definition of high altitude. High altitude is defined to begin at $1.5 \mathrm{~km}$ above sea level by the International Society of Mountain Medicine. Altitude illness, however, rarely occurs below $2.5 \mathrm{~km}$. In this article, we define high altitude to begin at $2.5 \mathrm{~km}$ above 
sea level, except as specifically clarified. The upper boundary of the earth's atmosphere is where outer space starts, but there is no clear definition of outer space either. The most common definition is that outer space starts at the Kármán line, which is $100 \mathrm{~km}$ above the surface of Earth (Becerra Ortiz, 2008). 99.99997\% of the atmosphere by mass is below $100 \mathrm{~km}$. By such definitions, the HAA starts from the upper troposphere, extends to the stratosphere and the mesosphere, and fades into space from the thermosphere (Fig. 1).

Transport mechanisms of microbes to the HAA

It is certain that there are microbes in the HAA. Earth's surface atmosphere contains various microbiota such as viruses, bacteria, algae, fungi and protozoa from a variety of sources (Brown et al., 1964; McGovern et al., 1965; Schlichting, 1969; Broady, 1979; Pósfai et al., 2003). The microbiota in the low altitude atmosphere, within troposphere, can get upward transportation via vertical atmospheric convection. Radar studies showed that some birds such as passerines fly at heights up to $3 \mathrm{~km}$ and wader up to $7 \mathrm{~km}$ during long migration flights (Bruderer, 1997). It is very likely that birds traveling at high altitude carry microbes and release them at that height. Since the late 1800's and early 1900's, human activities started to contribute the distribution of microbes into the HAA by balloons, aircrafts and rockets. Human skydivers might have also brought microbes up to the middle stratosphere (McCrory, 2004). Other mechanisms of transporting microbes into the HAA include wind storms (Kellogg and Griffin, 2006), volcanic ejection (Robock, 2002; Antuña et al., 2003; Oman et al., 2005) and meteorite impacts (Alvarez et al., 1980). Simulation study showed that, electric fileds found during thunderstorms could accelerate charged micro-sized particles rapidly up to the upper stratosphere against the forces of drag of neutral atmosphere and gravity (Dehel et al., 2008).

\section{Microbes in the HAA}

The presence of microbes in the HAA has been known for more than a century. However, the HAA remains a poorly explored area of microbiology. There is only fragmentary information about microbial populations in the HAA. A few samples have been collected in the HAA and the microbes in these samples were studied (Table 1). Fungi and pigmented endospore-forming bacteria from the high atmosphere were first reported in Europe (Cristiani, 1893; Harz, 1904). Later studies in the USA, Soviet Union, and India reported the recovery of fungi, and endospore-forming bacteria such as Bacillus (Rogers and Meier, 1936; Soffen, 1965; Bruch, 1967; Wainwright et al., 2003; Griffin, 2005), and non-sporeforming Micrococci and Mycobacterium (Fulton, 1966; Bruch, 1967; Imshenetsky et al., 1978; Griffin, 2008). We isolated Deinococci and endospore-forming bacteria from samples collected in the upper troposphere and stratosphere in Japan (Yang et al., 2008a, 2008b). Algae, viruses and protozoans have not been reported to date. Spore-forming bacteria and fungi were the predominant species of reported HAA isolates. The predominant nonspore-forming isolates reported were Micrococci, a group

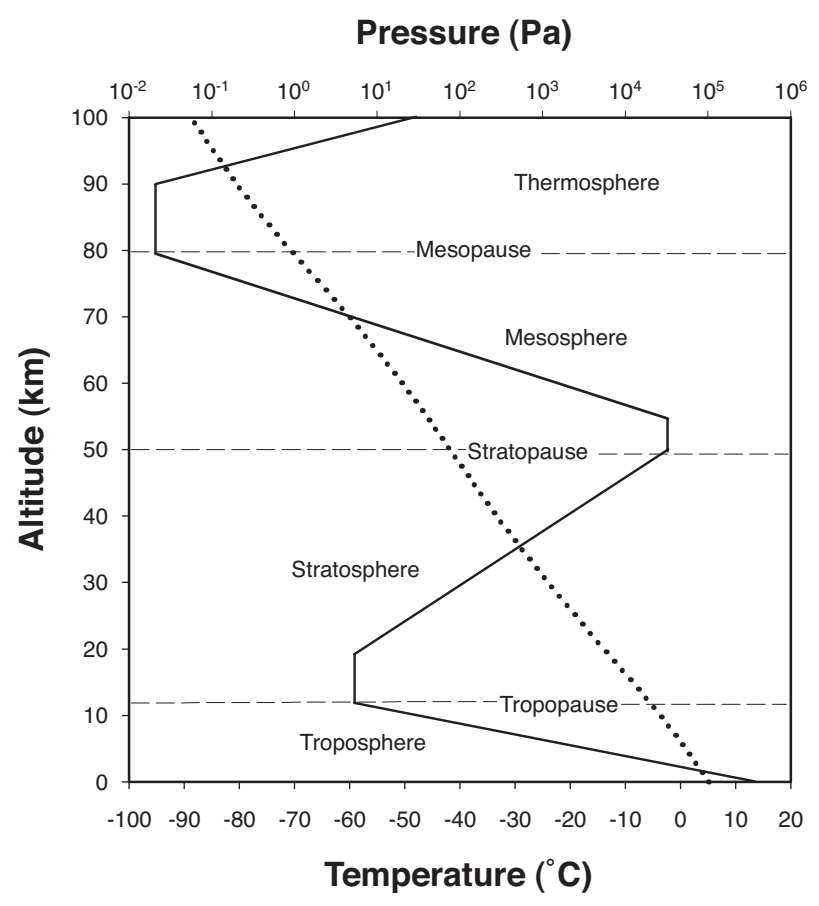

Fig. 1. Layers of the Earth's atmosphere. Changes in the average global atmospheric temperature (solid lines, simplified) and pressure (dotted line) with altitude are indicated.

to which the Deinococci previously belonged (Murray, 1992).

Due to their high resistance to desiccation and radiation, Bacillus spores and Deinococcus radiodurans cells have been frequently used in ground-based space research (Dose and Gill, 1995; Dose et al., 1996, 2001; Dose and Klein, 1996; Mancinelli and Klovstad, 2000; Horneck et al., 2001; Saffary et al., 2002; FajardoCavazos et al., 2005; Nicholson and Schuerger, 2005; Diaz and Schulze-Makuch, 2006; Tauscher et al., 2006; de la Vega et al., 2007; Stöffler et al., 2007; Osman et al., 2008) or exposure experiments in near-earth orbits (Horneck et al., 1995; Reitz et al., 1995; Brack et al., 2001; Rettberg et al., 2002a; Rabbow et al., 2003; Sancho et al., 2007). Since the microbes isolated from the HAA had high chance to escape from the earth and survive under outer space environment, they can be representatives of terrestrial microbes for panspermia. In particular, Bacillus and Deinococcus isolates from the HAA that exhibited high levels of radiation- and desiccation resistance (Shivaji et al., 2006; Yang et al., 2008b, 2009a, 2009b) would be good candidates for future tests of interplanetary transfer of life.

\section{Microbial concentrations in the HAA}

It is generally thought that population density of microbiota decreases with increasing altitude in the troposphere. However, the height dependence of microbial population density has not well been studied. From the available data on captured microbes (Table 1 ), we estimated the microbial density by the altitude at ambient temperature and pressure (ATP). The microbial 
Yang, Y. et al.

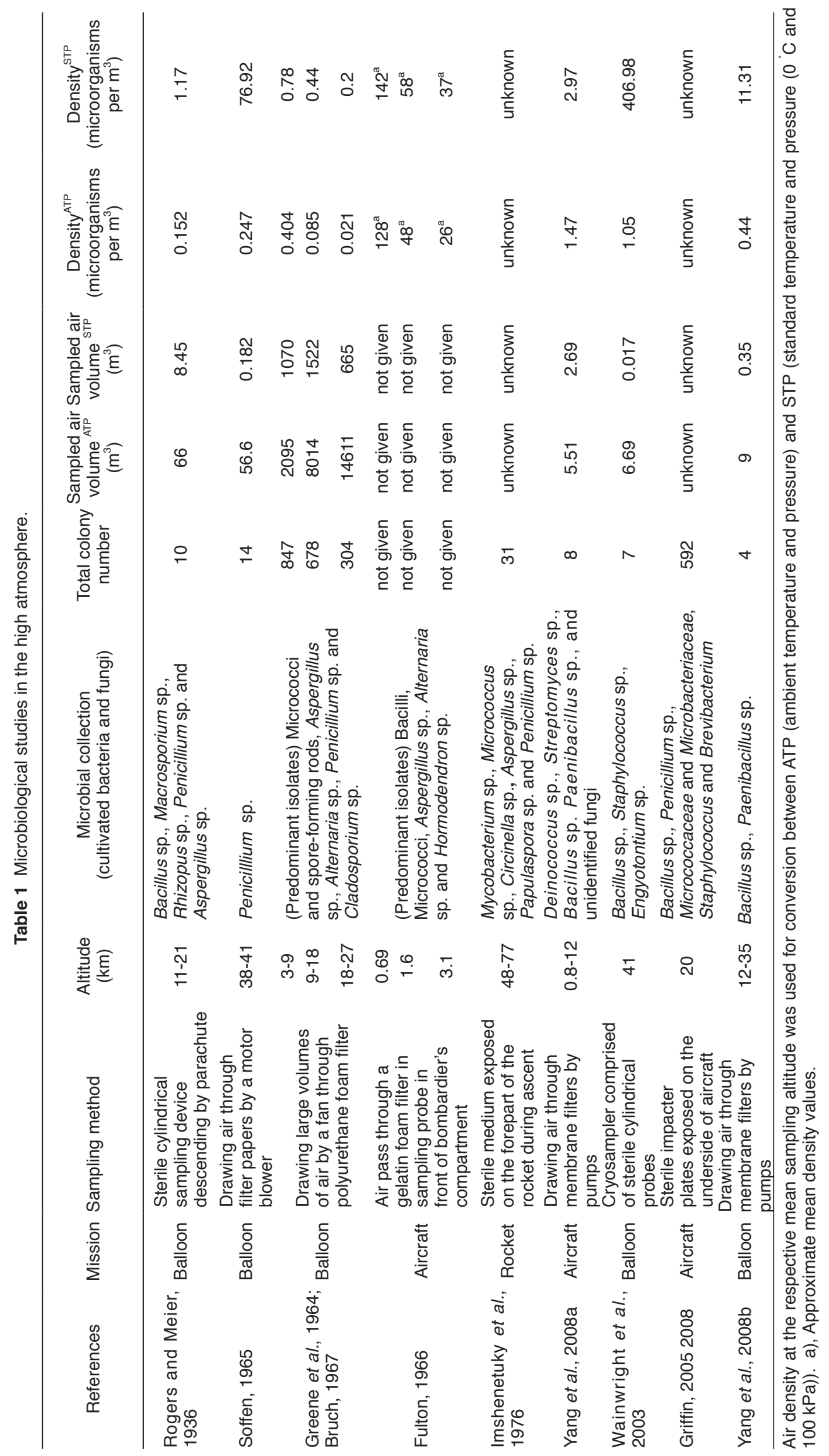




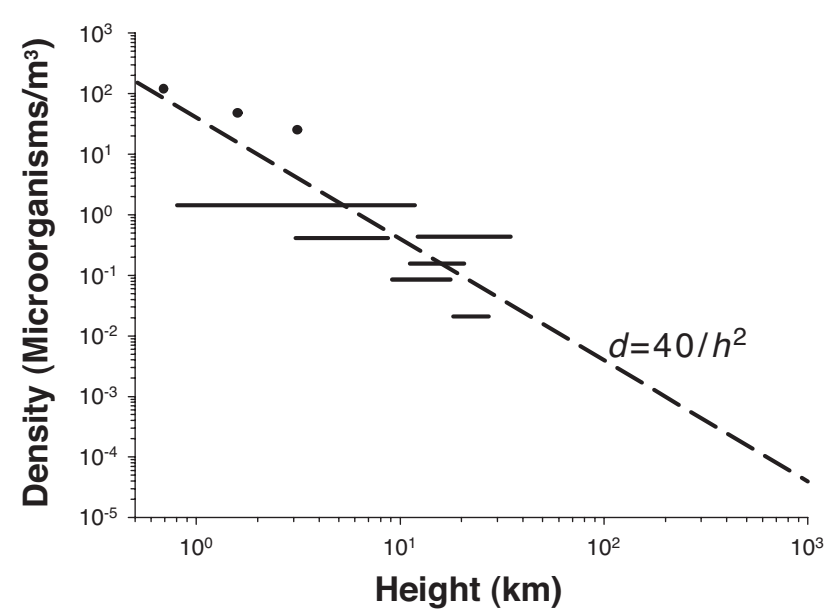

Fig. 2. Microbial density depending on altitude. Horizontal lines or filled circles were drawn based on the data at ambient temperature and pressure (ATP) in Table 1. Because some microbial samplings were done in certain height ranges, the horizontal lines show the respective height ranges. The dashed regression line $\left(d=40 / h^{2}\right)$ indicates the estimated microbial density $(d)$ versus height $(h)$.

density data above $35 \mathrm{~km}$ in Table 1 was not used in the estimation, due to the small volumes of air collected (less than $\left.0.2 \mathrm{~m}^{3}, \mathrm{STP}\right)$. The estimated result was close to the regression line $d=40 / h^{2}$ (Fig. 2), where $d$ is the microbial density and $h$ is the altitude in $\mathrm{km}$. It suggests that microbial density generally decreases at higher altitudes over the troposphere. At the top of the atmosphere (100 $\mathrm{km}$ altitude), the expected microbial density is at an order of $10^{-2} \sim 10^{-3} / \mathrm{m}^{3}$. The altitude-dependence of microbial density in Fig. 2 must be taken to be a rough estimate, however, since microbial density data at specific altitudes from independent investigations may have ambiguity due to various factors such as variable atmospheric conditions, sampling methods, and even the isolation media used. More data, particularly in the atmosphere higher than $25 \mathrm{~km}$, is needed to obtain a better understanding of the microbial distribution in the HAA. It is worth emphasizing that the data in Fig. 2 is limited to cultivated microbes, although generally less than $1 \%$ of the microbes in the natural environment can be cultivated. Wainwright et al. (2004) found non-cultivable bacterial clumps in HAA samples using viable fluorescent staining. The actual density of microbes at various altitudes might be two orders of magnitude higher than that shown in Fig. 2 .

\section{Microbial Survival under HAA Conditions}

The physical environment in the HAA is harsher than the low altitude atmosphere, not only in temperature, humidity, density and pressure, but also in the levels of various types of radiation. Micro-sized particles such as bacteria and spores drifting over the tropopause may take 1-2 years to sediment on Earth's surface, while the residence time in the upper troposphere is typically weeks (Kirkby and Carslaw, 2006). Although the atmospheric environment generally does not support microbial growth, some microbes, particularly those isolated from the HAA, are presumably able to survive in the harsh environment for at least weeks to years.

\section{Survival under HAA thermal environment}

Air temperature profile in the atmosphere is a major criterion for the definition of atmospheric layers (Fig. 1). The temperature in the troposphere and the mesosphere decreases as altitude increases. The temperature increases as altitude increases in the stratosphere and the thermosphere. At high altitude, the atmospheric temperature is usually lower than the freezing point of water. However, the situation is not simple for the particles at higher altitude due to dramatically decreasing air density. Ambient temperature of dilute air or charged particles does not determine the temperature of the particles in situ. Thermal environment for microbe in the HAA is dominated by radiative heating made by solar light and long wave emission from Earth surface and radiative cooling of microbe to deep space $(3 \mathrm{~K})$. Since the heat input has daily cycle, the temperature of particles is high during day time and low at night, thus the heat cycle will affect the microbial survival in the HAA. Escherichia coli, a bacterium widely distributed on Earth's surface but never isolated from the HAA to date, is susceptible to subzero temperatures and is severely damaged, probably due to the presence of fragile cell components such as the cytoplasmic membrane (Moussa et al., 2008). Some microbes may exhibit metabolic activity below $0{ }^{\circ} \mathrm{C}$ and even grow in clouds (Carpenter et al., 2000; Sattler et al., 2001; Hansen et al., 2007). Bacillus spores and Deinococci, the species frequently found in the HAA, are rarely inactivated by subzero temperatures (Diaz and Schulze-Makuch, 2006; Yang et al., 2009c); rather, they are better preserved at $-70{ }^{\circ} \mathrm{C}$ (Yang et al., 2009c). However, the effect of the daily temperature cycle on microbes has not been assessed.

\section{Survival under HAA desiccation conditions}

Water is a crucial element for terrestrial life. Water vapor content in the troposphere usually varies with weather and location. Its partial pressure decreases rapidly with altitude, varying from several thousand $\mathrm{Pa}$ near the surface to seveal hundred milli $\mathrm{Pa}$ in the lower stratosphere (Seidel, 2002). Above the tropopause, the atmosphere becomes almost completely dry. Atmospheric dryness at high altitude is caused not only by the scarcity of water, but also the low atmospheric pressure (Fig. 1). Drying of microbes proceeds when they are heated by solar radiation in vacuum. In solar system, a snow line (2.7 of Earth revolution radius) is defined whether water stays as ice or not. It depends on the temperature of the body under the radiation heat balance. Under $150 \mathrm{~K}$ or so, water stays in ice form. Around Earth or even Mars, volatile chemical species sublimate by solar radiation, while sublimation of water does not occur beyond the snow line.

Microbes exhibit very different levels of resistance to desiccation. Some (e.g. Bacillus spores) may survive up to a million years but some die within several hours under desiccation (Atlas and Bartha, 1997). Presumably, 


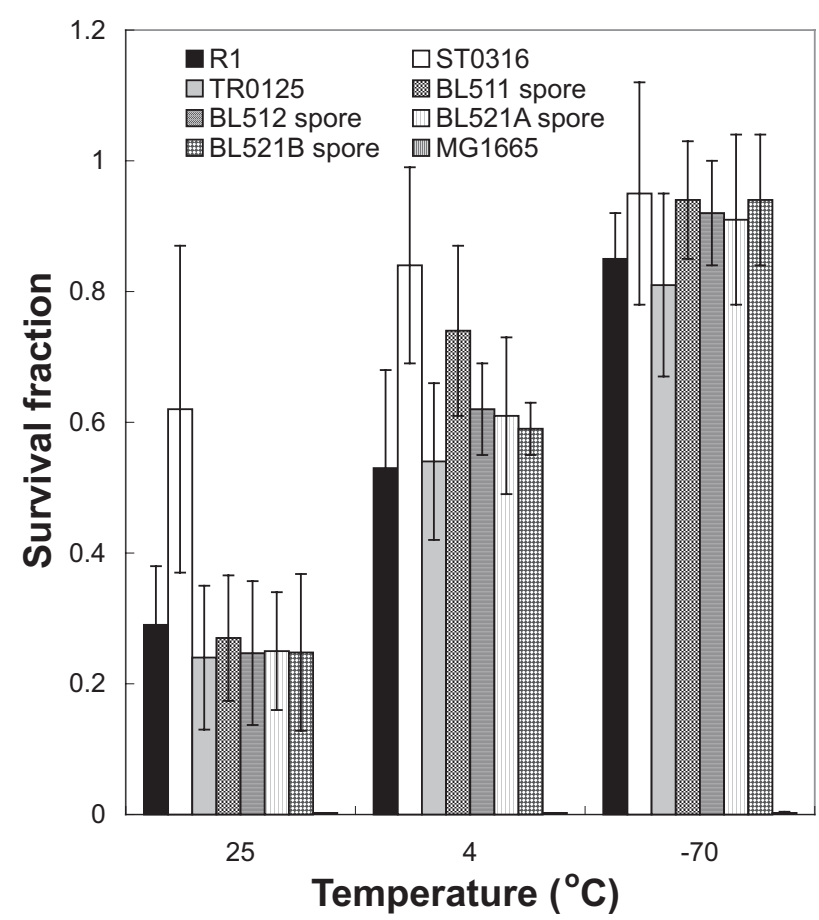

Fig. 3. Bacterial survival after 6-weeks of desiccation. Materials and methods were described previously (Yang et al., 2009c). Strain $\mathrm{R} 1$ ( $D$. radiodurans) is a ground isolate well known for desiccation tolerance. Deinococcus strains ST0316 and TR0125, Bacillus strains BL511, BL512, BL521A, and BL521B, are the isolates we obtained from the HAA (Yang et al., 2008a, 2008b). Strain MG1665 (E. coli) is an Earth surface isolate, which is sensitive to desiccation, and its survival fraction was quite low as indicated in this figure. Data for each strain was from at least three independent experiments.

high resistance to desiccation is needed for microbial survival in the HAA. Desiccation-sensitive microbes would not be able to survive in the HAA for long peroids. However, little is known about the desiccation resistance of HAA microbes, as the desiccation resistance of HAA isolates has not been evaluated in previous studies. To gain knowledge regarding the desiccation resistance of HAA microbes, the isolates we obtained from the HAA were exposed to dessication conditions for six weeks. All of the tested HAA isolates showed greater desiccation resistance than the earth's surface isolate $E$. coli (Fig. 3). In particular, the Deinococci readily survived desiccation conditions (Yang et al., 2009c) and may persist in the HAA for extended periods. Deinococci are well known for radiation resistance, which largely results from their extraordinary ability to repair DNA (Cox and Battista, 2005). High intracellular manganese and low iron concentrations in Deinococci were suggested to facilitate cellular protection from protein oxidation during dehydration and radiation (Daly et al., 2004; Fredrickson et al., 2008). A correlation between desiccation and radiation resistance of Deinococci has been suggested by seveal studies (Mattimore and Battista, 1996; Tanaka et al., 2004; Rainey et al., 2005; Chanal et al., 2006). A major reason for radiation and desiccation resistance of bacterial endospores is likely the protection of spore DNA by a/ $\beta$-type small acid-soluble proteins (Nicholson et al., 2000).

\section{Survival in ozone-containing $H A A$}

Up to the upper boundary of the atmosphere, there is almost no change in the relative composition of dry air (78 $\%$ nitrogen, $21 \%$ oxygen, $1 \%$ argon, and trace gases) except for ozone, whose composition is high in the stratosphere. The average concentration of ozone in the stratosphere is about $10 \mathrm{ppm}$ compared to approximately $0.04 \mathrm{ppm}$ in the troposphere. Many microbes may be killed within minutes by similar level of ozone as in the stratosphere (Li and Wang, 2003; Young and Setlow, 2004; Tseng and Li, 2006). However, the toxicity of ozone is greatly affected by environmental factors such as relative humidity and temperature. Lower temperature may decrease ozone effectiveness on the microbes (Wickramanayake and Sproul, 1988). Microbes were killed more readily by ozone in an atmosphere having a high rather than low relative humidity (Ewell, 1946). At relative humidity $<45 \%$, the germicidal power of ozone on airborne microbes was negligible (Elford and van de Eude, 1942). It seems that moisture in a cell is needed to be inactivated by ozone. Not only that desiccated microbes are more resistant than hydrated cells to ozone, but once desiccated, some cells are difficult to rehydrate sufficiently to be susceptible to ozone sterilization (Guérin, 1963). Considering the subzero temperature and extremely low water vapor content in the stratosphere, it is not likely that stratospheric ozone directly inactivates microbes.

\section{Survival at HAA pressure}

Atmospheric pressure decreases with increasing altitude (Fig. 1). About $2.5 \mathrm{kPa}$ (corresponding to the atmospheric pressure at about $25 \mathrm{~km}$ altitude) may be the lower limit for bacterial growth (Thomas et al., 2006). The associated desiccation at low atmospheric pressure may also affect microbial viability and therefore may play a role in selecting for survivors in the HAA. It was reported that increasing levels of desiccation during vacuum caused DNA damage (Dose et al., 1991; Dose and Gill, 1995; Wehner and Horneck, 1995). Desiccation stress induces reactive oxygen species, which can cause irreversible damage on membrane systems, proteins and DNA (Mattimore and Battista, 1996; Adhikari et al., 2009). Under extremely low pressures (high vacuum), survival rates of microbes can be very different depending on the species and strains (Imshenetsky et al., 1977; Horneck, 1981; Dose et al., 1996; Miyamoto-Shinohara et al., 2000; Saffary et al., 2002). Many bacteria can turn into dormancy (a reversible state of very low metabolic activity) to survive subzero temperature and high vacuum (Mileikowsky et al., 2000; Bar et al., 2002; Price and Sowers, 2004). Bacterial DNA is hardly damaged by the stable low temperature and stable dry state. Freezing down to the temperature of liquid nitrogen and vacuum are often used to store bacteria for long periods. Much higher bacterial survival in response to low pressures occurs at subzero temperature compared to temperatures above zero, and in Bacillus spores and Deinococci 
compared to E. coli (Dose and Klein, 1996; Diaz and Schulze-Makuch, 2006).

\section{Survival under radiation in the HAA}

Another serious challenge for microbial survival in the HAA is thought to be radiation. Cosmic ray in the HAA originates from the sun and galactic system. The composition and fluence of cosmic ray vary throughout the atmosphere, partially depending on the altitude (Eisenbud, 1987; Bouville and Lowder, 1988). The level of cosmic radiation in the HAA is generally too low to be a threat for microbes. At spacecraft altitude, the dose of cosmic radiation averages about $0.2 \mathrm{mGy}$ per day (Goossens et al., 2006), while about 100 Gy is necessary to inactivate $37 \%$ of E. coli (Quint et al., 2002), a bacterium that is very radiation-sensitive compared to bacterial isolates from the HAA (Yang et al., 2009b). Cosmic rays are thought to be much less effective in damaging terrestrial life than UV radiation (Galante and Horvath, 2007).

The ultraviolet section $(<400 \mathrm{~nm})$ of the solar radiation spectrum accounts for about $7 \%$ of total solar radiation. With every $1 \mathrm{~km}$ increase in altitude, UV levels generally increase by 10 to $20 \%$, depending on latitude, weather, and time of day and year (Blumthaler et al., 1997; Seckmeyer et al., 1997; Schmucki and Philipona, 2002; World Health Organization, 2002). The microbes that survive in the HAA are presumably resistant to ambient UV radiation. Considering the increase of biologically effective irradiation at high altitudes (Nybakken et al., 2004), and the higher susceptibility of some microbes to the combined effects of radiation and other factors such as vacuum (Saffary et al., 2002; Diaz and Schulze-Makuch, 2006), a lethal radiation dose for some microbes could be reached at altitudes in the HAA. However, data on UV resistance is available for few isolates from the HAA. The microbes isolated by Imshenetsky et al. (1976) were found to be very resistant to UV radiation, with the exception of the unpigmented Micrococcus albus (Imshenetsky et al., 1977). The four Bacillus strains isolated from the HAA by Shivaji et al. (2006) were also claimed to be very UV-resistant. Shivaji et al. also related the UV resistance of their isolates with more intense UV radiation in the HAA than on the ground. The bacterial isolates we obtained from the HAA by aircraft exhibited higher UV resistance than the ground isolates from campus and the airport (Yang et al., 2008a). Besides containing pigments, the Deinococcus isolates from the HAA (Yang et al., 2008a) tended to form cell clumps or aggregates, which might help their survival under UV radiation. The presence of viable cell clumps has been reported from the samples collected in the upper stratosphere (Harris et al., 2001). Also, spores of the isolates we obtained from the HAA by balloon generally exhibited greater UV resistance compared to E. coli (Yang et al., 2008b). Therefore, it is likely that UV radiation plays a crucial role in selecting microbial species able to survive in the HAA.
Overall, typical HAA conditions such as Iow temperature, desiccation, low pressure or radiation, alone or in some combination, may affect the survival of microbes to varying degrees. This is consistent with the isolation of vial spore-formers and Deinococci from the HAA, as these organisms are generally much more resistant to these conditions than $E$. coli. It is worth noting that the actual conditions in the HAA result from the combination of all individual HAA conditions. Survival of microbes in the HAA is determined by a synergistic effect of these conditions, rather than on a single condition, and the synergistic effect is not simply the additive effect of the single conditions.

\section{Microbial Survival from the HAA to Outer Space}

Most of the physical conditions of outer space resemble those of the upper atmosphere. The radiation of outer space, which is different from that of the HAA in spectra and density, is considered to be a most serious threat for microbial survival during interplanetary transfer. Extraterrestrial UV radiation can kill unprotected $B$. subtilis spores within seconds (Horneck and Brack, 1992). Since unprotected microbes rarely survive a long trip in space, lithopanspermia (interplanetary transfer of life inside meteorites) is thought to be more likely (Clark et al., 1999; Mileikowsky et al., 2000) and will be tested by the Living Interplanetary Flight Experiment (Warmflash et al., 2007). However, some microbes might form cell clusters or carried by airborne or cosmic dusts or meteorites as their inclusion. The dusts or outer layers of cell clusters might provide some protection from extraterrestrial radiation to the cells inside. Bacterial spores, if protected by dead spores or a dust layer of just a few microns to centimeters thick, could survive solar UV exposure for a significantly longer period (Mancinelli and Klovstad, 2000; Rettberg et al., 2002b). Microbes therefore might not require meteorites for their carrier to survive during space travel. Thermal environment determined by intensity of solar light could be another serious challenge for unprotected microbes during interplanetary transfer. The heat-resistant bacteria would have more chances to survive the thermal environment. Some Deinococci can grow at about $55{ }^{\circ} \mathrm{C}$ (Ferreira et al., 1997). Their lethal temperatures have not been reported. Endospores of many bacterial species can sustain heat treatment higher than $80^{\circ} \mathrm{C}$. E. coli in desiccated state exposed to short heating pulses under vacuum conditions survived up to $250{ }^{\circ} \mathrm{C}$, while the same heating under atmospheric pressure led to complete sterilization (Pavlov et al., 2007). It is unknown that up to which high temperature desiccated Deinococci and spores can tolerate under vacuum condition. Microbes traveling opposite to the sun would suffer less solar heat. If microbes are ejected from Earth and travel at the high speeds as suggested by Dehel (2006), the traveling time to Mars or Titan could be less than 1 year. 


\section{Landing of HAA Microbes onto Extraterrestrial Bodies}

The panspermia process may be divided into three phases, i.e. 1) ejection from a donor planet, 2) transit through interplanetary space, and 3) entry and landing onto a recipient planet (Mileikowsky et al., 2000; Nicholson, 2004). Terrestrial microbes, particularly spores and Deinococci, can be transported into the HAA and viably ejected from Earth for space travel as discussed above. The gravitational field of another planet may increase chance of capturing panspermian carrier. Aerodynamical heat or shock suffered during their ascent or descent is a major factor contributing to killing of microbes (Fajardo-Cavazos et al., 2005; Meyer et al., 2006). For extraterrestrial bodies to capture small microbe-associated particles (SMP), however, their speed relative to the target body might be more important than the additional speed gained by gravitational potential. Survival during atmospheric entry is largely dependent on the size and entry speed of the particles, and thickness of the atmosphere. Generally, the smaller and slower particles survive intact. For particles entering the earth's atmosphere at speeds $<20 \mathrm{~km} / \mathrm{s}$ the survival rate is essentially $100 \%$ for diameter $<5 \mu \mathrm{m}$ and is less than 50 $\%$ for diameter $>100 \mu \mathrm{m}$ (Brownlee, 2001). In the case of extraterrestrial bodies with thick atmospheres (e.g. Mars and Titan), entry of SMP can be largely buffered, provided adequate injection angle, thus their viable landing on the bodies is likely. In the case of collision with bodies with thin atmospheres (e.g. Mercury and the Moon), SMP would likely experience accelerated impact on the surface. Survivability of microbes after high impact collision has been tested (Horneck et al., 2001; Mastrapa et al., 2001; Benardini et al., 2003; Willis et al., 2006). Large fractions of spores or Deinococci survived impact with hard surfaces at the impact speeds less than $1 \mathrm{~km} / \mathrm{s}$. Survivability of $E$. coli after exposure to shock wave was much lower than Bacillus spores and Deinococcus.

Microbes could have been launched with our space probes or ejected by meteorite impacts into outer space at high speeds. A sustained 'outflow' of microbes into near-earth space propelled by electromagnetic fields and further into deep space via magnetospheric plasmoids that leave the Earth at $700 \mathrm{~km} / \mathrm{s}$ or more have been suggested (Håland et al., 1999; Dehel, 2006), although the modeling study has not been done above the stratosphere (Dehel et al., 2008). Ejected microbes may travel interplanetary space freely after leaving the Earth gravitational potential well under gravitational force of Sun until leaving its gravitational potential well. Depending on size and composition of the ejected microbes, their interplanetary travel may also be propelled outward from Sun by radiation pressure force (Wilck and Mann, 1996). Therefore, microbes might be widely present in deep space and some may have reached other planets.

The density of terrestrial microbes dispersed to distant space would be inverse square proportional to the distance from Earth. Since the regression line of microbial density at the vicinity of Earth happens to show inverse square dependence on the height from Earth surface, same regression line $\left(d=40 / h^{2}\right.$, replacing $h$ with distance) was applied to estimate density of terrestrial microbes hitting the extraterrestrial bodies such as Moon, Mars and Titan listed in Table 2. We further estimated the amount of microbes that could encounter these bodies. The total number of microbes that annually encounter a body was estimated by the multiplication of microbial density at the body's altitude (microorganims $/ \mathrm{km}^{3}$ ), moving speed $(\mathrm{km} /$ s) of the body in our Solar system, and the largest cross section $\left(\mathrm{km}^{2}\right)$ of the body. The Moon could trap $7.5 \times$ $10^{13}$ microbes per year. If microbial decay were avoided on some Moon areas, microbial density on the Moon would be high after accumulation for billions of years. The craters in permanent shadow near the lunar poles can be of astrobiological interest. Mars and Titan could trap fewer amounts of terrestrial microbes per year. If hospitable conditions (e.g. water or methane) for microbial growth existed or still exist on Mars and Titan, even the amount of seed microbes might be small, but flourished in some regions of the bodies once viable transfer was achieved.

\section{Challenges}

\section{Sampler carriers}

Microbial sampling in the HAA requires sampler carriers such as aircraft, balloon or rocket. These

Table 2 Estimated microorganisms in outer space and yearly deposition on some extraterrestrial objects.

\begin{tabular}{cccccc}
\hline Object & $\begin{array}{c}\text { Mean distance from } \\
\text { Earth's surface }(\mathrm{km})\end{array}$ & $\begin{array}{c}\text { Extrapolated microbial } \\
\text { density at the distance } \\
(\text { microorganisms/km })\end{array}$ & $\begin{array}{c}\text { Average moving speed of } \\
\text { the object }(\mathrm{km} / \mathrm{s})\end{array}$ & $\begin{array}{c}\text { Target cross section } \\
\text { of })\end{array}$ & $\begin{array}{c}\text { Expected encounter } \\
(\text { microorganisms/year })\end{array}$ \\
\hline ISS & $3.5 \times 10^{2}$ & $3.3 \times 10^{5}$ & $7.7^{\mathrm{b})}$ & - & - \\
Moon & $4.0 \times 10^{5}$ & $2.5 \times 10^{-1}$ & $1.0^{\mathrm{b})}$ & $9.5 \times 10^{6}$ & $7.5 \times 10^{13}$ \\
Mars & $2.3 \times 10^{8}$ & $7.6 \times 10^{-7}$ & $24^{\mathrm{c})}$ & $3.6 \times 10^{7}$ & $2.1 \times 10^{10}$ \\
Titan & $1.4 \times 10^{9}$ & $2.0 \times 10^{-8}$ & $9.7^{\mathrm{d})}$ & $2.1 \times 10^{7}$ & $1.3 \times 10^{8}$ \\
\hline
\end{tabular}

a) Target cross section is assumed to be $\pi \times r^{2}(r$, mean radius of the object).

b) Orbital speed around the Earth.

c) Orbital speed around the sun.

d) Saturn's orbital speed around the sun. 
requirements have greatly limited sampling opportunities. Cooperation with carrier administrators and operators is necessary for conducting such flight experiment. The cost of a flight is usually much higher than that of the biological investigation. Among them, the cost for aircraft is the least, while the cost for rocket is the most.

There is always concern that the carrier may introduce contamination. Preventing contamination by carriers remains a difficult task. Although the sampler may be thoroughly sterilized before launch and kept clean before sampling in the HAA, it is not feasible to completely sterilize the carrier. Strictly speaking, it is impossible to absolutely avoid potential contamination from the carrier, as long as the sampler is sent with the carrier from the ground and operated close to the carrier in the HAA. For samplings facilitated by aircraft (Fulton, 1966; Griffin, 2005; Yang et al., 2008a) or rocket (Imshenetsky et al., 1978), the probability of such contamination was low, since the air collectors were positioned at the forward (ram) direction of the high-speed carrier. Furthermore, sterilization of the rocket was reached by the heating (up to $600{ }^{\circ} \mathrm{C}$ ) during its high speed take-off through dense air (Imshenetsky et al., 1978). However, the probability of contamination from balloons is relatively high, since the air collectors are usually hung below the slowly ascending balloons (Rogers and Meier, 1936; Greene et al., 1964; Soffen, 1965; Wainwright et al., 2003; Yang et al., 2008b). To evaluate sampling reliability using a balloon, we recommend that future investigations include control sampling from the balloon surface immediately before launch, and an air sample before reaching the designated sampling altitude. Sampling without contamination by the carrier might be achieved by dropping a sampling device after being carried to the HAA, but sampling time and therefore the air volume would be very limited in this case.

\section{Microbial collection and detection methods}

Standard methodology has not yet established for microbial investigation in the HAA. Various samplers have been designed and used in past studies. Some included air filter papers or impact media, while some collected only air for later processing in the laboratory. Collecting efficiency could depend on the types of filter papers or impact media used. In addition, the volumes of air impacted with media were unknown. The methods for recovering microbes from the samples (culture media and conditions) were also different. Therefore, it is difficult to compare the microbiology data among the various studies. There is a need to standardize or develop adequate types of filter papers (pore size and material) for studying the HAA microbes. If multiple parallel sampling can be conducted in future studies, several types of culture media and conditions should be used for microbe isolation.

Determination of the overall microbial diversity in the HAA is essential for our full understanding of which microbes may spread around the earth via the HAA and possess the potential for traveling to outer space. As discussed above, many species of microbes have been isolated in past investigations. However, the vast majority of microbial diversity might have been limited by cultivation-based methods. Little has been done to determine the diversity of non-cultivable microbes in HAA samples. The presence of viruses, which are the smallest microbes, has rarely been investigated in the HAA, although they may stay in the HAA for longer periods of time than larger microbes. Culture-independent techniques such as 16S rRNA gene sequence analysis and metagenomic sequencing can provide a less biased perspective on HAA microbes. One challenge is the low concentration of HAA microbes. Large numbers of microbes might be collected on filter membranes by filtering huge volumes of air with deployment of powerful sampling devices and extended sampling times; however, this strategy would be more costly. In the case of few microbes in the sample, micromanipulation and single cell techniques (Brehm-Stecher and Johnson, 2004), which have been used to facilitate the isolation of pure eukaryotic cells or prokaryotic cultures, may be necessary.

\section{Perspective}

The stress resistance of the spore formers and vegetative Deinococci explains their prevalence in the harsh HAA environment. Applying culture-independent techniques might result in the discovery of more microbial populations in the HAA. Exposing laboratory-prepared microbes to the HAA may test the synergistic effects of atmospheric conditions on their survival. Sampling by using a rocket (Imshenetsky et al., 1978) has been the sole method for investigation at altitudes higher than $50 \mathrm{~km}$. Development of balloons capable of flying at altitudes higher than $50 \mathrm{~km}$ (Yamagami et al., 2004) makes it possible to conduct more investigations at the top of the earth's atmosphere. For collection of HAA microbes facilitated by high-speed aircraft or rockets, it is worth testing another medium (Aerogel), which has been used to capture micrometeoroids and debris in outer space (Hörz et al., 2000), and simulate aero-capture in a planetary atmosphere (Burchell et al., 2001). Detection of microbes that may have escaped from Earth and testing of microbial survival at International Space Station (ISS) altitude for multi-year periods constitute goals of the TANPOPO project (Yamagishi et al., 2007). Invaluable information on the 'Panspermia' of terrestrial life might be obtained from the project.

\section{Acknowledgement}

Dr. Satoshi Akanuma assisted us on reading articles in German.

\section{References}

Adhikari, B.N., Wall, D.H. and Adams, B.J. (2009) Desiccation survival in an Antarctic nematode: molecular analysis using expressed sequenced tags, 
BMC Genomics, 10, 69.

Alvarez, L.W., Alvarez, W., Asaro, F. and Michel, H.V. (1980) Extraterrestrial cause for the CretaceousTertiary extinction, Science, 208, 1095-1108.

Antuña, J.C., Robock, A., Stenchikov, G., Zhou, J., David, C., Barnes, J. and Thomason, L. (2003) Spatial and temporal variability of the stratospheric aerosol cloud produced by the 1991 Mount Pinatubo eruption, J. Geophys. Res., 108, 4624.

Arrhenius, S. (1903) Die Verbreitung des Lebens im Weltenraum, Die Umschau, 7, 481-485.

Atlas, R.M. and Bartha, R. (1997) Microbial Ecology: fundamentals and applications, 4th ed. Benjamin/ Cummings Publishing Company, Inc., California.

Bandfield, J.L. (2007) High-resolution subsurface waterice distributions on Mars, Nature, 447, 64-67.

Bar, M., von Hardenberg, J., Meron, E. and Provenzale, A. (2002) Modelling the survival of bacteria in drylands: the advantage of being dormant, Proc. Biol. Sci., 269, 937-942.

Becerra Ortiz, J.A. (2008) A survey of Colombia's new outer space policy: Reforms in Colombian law, Acta Astronaut., 63, 560-563.

Benardini, J.N., Sawyer, J., Venkateswaran, K. and Nicholson, W.L. (2003) Spore UV and acceleration resistance of endolithic Bacillus pumilus and Bacillus subtilis isolates obtained from Sonoran desert basalt: implications for lithopanspermia, Astrobiology, 3, 709717.

Blumthaler, M., Ambach, W. and Ellinger, R. (1997) Increase in solar UV radiation with altitude, J. Photochem. Photobiol., 39, 130-134.

Bouville, A. and Lowder, W.M. (1988) Human population exposure to cosmic radiation, Radiat. Prot. Dosimetry, 24, 293-299.

Brack, A., Horneck, G. and Wynn-Williams, D. (2001) Exo/Astrobiology in Europe, Orig. Life Evol. Biosph., 31, 459-480.

Brehm-Stecher, B.F. and Johnson, E.A. (2004) Single-cell microbiology: tools, technologies, and applications, Microbiol. Mol. Biol. Rev., 68, 538-559.

Broady, P.A. (1979) Wind dispersal of terrestrial algae at Signy Island, South Orkney Islands, British Antarctic Survey Bull., 48, 99-102.

Brown, R.M., Jr., Larson, D.A. and Bold, H.C. (1964) Airborne algae: Their abundance and heterogeneity, Science, 143, 583-585.

Brownlee, D.E. (2001) The origin and properties of dust impacting the earth. In: Peucker-Ehrenbrink, B. and Schmitz, B. (Eds.), Accretion of extraterrestrial matter throughout Earth's history, Kluwer Academic/Plenum Publishers, New York.

Bruch, C.W. (1967) Microbes in the upper atomosphere and beyond. In: Gregory, P.A. and Monteith, J.L. (Eds.), Airborne microbes: symposium of the society of general microbiology. Cambridge University Press, London, pp. 345-373.
Bruderer, B. (1997) The study of bird migration by radar. Part 2: Major achievements, Naturwissenschaften, $\mathbf{8 4}$, 45-54.

Burchell, M.J., Shrine, N.R., Mann, J., Bunch, A.W., Brandao, P., Zarnecki, J.C. and Galloway, J.A. (2001) Laboratory investigations of the survivability of bacteria in hypervelocity impacts, Adv. Space Res., 28, 707712.

Carpenter, E.J., Lin, S. and Capone, D.G. (2000) Bacterial activity in South Pole snow, Appl. Environ. Microbiol., 66, 4514-4517.

Chanal, A., Chapon, V., Benzerara, K., Barakat, M., Christen, R., Achouak, W., Barras, F. and Heulin, T. (2006) The desert of Tataouine: an extreme environment that hosts a wide diversity of microorganisms and radiotolerant bacteria, Environ. Microbiol., 8, 514-525.

Clark, B.C., Baker, A.L., Cheng, A.F., Clemett, S.J., McKay, D., McSween, H.Y., Pieters, C.M., Thomas, P. and Zolensky, M. (1999) Survival of life on asteroids, comets and other small bodies, Orig. Life Evol. Biosph., 29, 521-545.

Cox, M.M. and Battista, J.R. (2005) Deinococcus radiodurans - the consummate survivor, Nat. Rev. Microbiol., 3, 882-892.

Crick, F.H.C. and Orgel, L.E. (1973) Directed Panspermia, Icarus, 19, 341-346.

Cristiani, H. (1893) Analyse bacteriologique de l'air des hauteurs, puise pendant un voyage en ballon, $A$. l'Inst. Pasteur, 7, 665-671.

Daly, M.J., Gaidamakova, E.K., Matrosova, V.Y., Vasilenko, A., Zhai, M., Venkateswaran, A., Hess, M., Omelchenko, M.V., Kostandarithes, H.M., Makarova, K.S., Wackett, L.P., Fredrickson, J.K. and Ghosal, D. (2004) Accumulation of $\mathrm{Mn}$ (II) in Deinococcus radiodurans facilitates gamma-radiation resistance, Science, 306, 1025-1028.

de la Vega, U.P., Rettberg, P. and Reitz, G. (2007) Simulation of the environmental climate conditions on martian surface and its effect on Deinococcus radiodurans, Adv. Space Res., 40, 1672-1677.

Dehel, T. (2006) Charged bacterial spore uplift and outflow via electric fields, $36^{\text {th }}$ COSPAR Scientific Assembly, Beijing, China.

Dehel, T., Lorge, F. and Dickinson, M. (2008) Uplift of microorganisms by electric fields above thunderstorms, J. Electrostat., 66, 463-466.

Diaz, B. and Schulze-Makuch, D. (2006) Microbial survival rates of Escherichia coli and Deinococcus radiodurans under low temperature, low pressure, and UV-Irradiation conditions, and their relevance to possible Martian life, Astrobiology, 6, 332-347.

Dose, K., Biege-Dose, A., Dillmann, R., Gill, M., Kerz, O., Klein, A. and Stridde, C. (1996) UV photobiochemistry under space conditions, Adv. Space Res., 18, 51-60.

Dose, K., Bieger-Dose, A., Ernst, B., Feister, U., GomezSilva, B., Klein, A., Risi, S. and Stridde, C. (2001) Survival of microorganisms under the extreme 
conditions of the Atacama Desert, Orig. Life Evol. Biosph., 31, 287-303.

Dose, K., Bieger-Dose, A., Kerz, O. and Gill, M. (1991) DNA-strand breaks limit survival in extreme dryness, Orig. Life Evol. Biosph., 21, 177-187.

Dose, K. and Gill, M. (1995) DNA stability and survival of Bacillus subtilis spores in extreme dryness, Orig. Life Evol. Biosph., 25, 277-293.

Dose, K. and Klein, A. (1996) Response of Bacillus subtilis spores to dehydration and UV irradiation at extremely low temperatures, Orig. Life Evol. Biosph., 26, 47-59.

Eisenbud, M. (1987) Environmental radioactivity. Academic Press, Inc., London, pp. 121-172.

Elford, W.J. and van de Eude, J. (1942) An investigation of the merits of ozone as an aerial disinfectant, J. Hyg., 42, 240-265.

Ewell, A.W. (1946) Recent ozone investigation. J. Appl. Phys., 17, 908-911.

Fajardo-Cavazos, P., Link, L., Melosh, H.J. and Nicholson, W.L. (2005) Bacillus subtilis spores on artificial meteorites survive hypervelocity atmospheric entry: implications for Lithopanspermia, Astrobiology, 5, 726-736.

Ferreira, A.C., Nobre, M.F., Rainey, F.A., Silva, M.T., Wait, R., Burghardt, J., Chung, A.P. and da Costa, M.S. (1997) Deinococcus geothermalis sp. nov. and Deinococcus murrayi sp. nov., two extremely radiationresistant and slightly thermophilic species from hot springs, Int. J. Syst. Bacteriol., 47, 939-947.

Fox, S.W. (1973) Origin of the cell: Experiments and premises, Naturwissenschaften, 60, 359-368.

Fredrickson, J.K., Li, S.M., Gaidamakova, E.K., Matrosova, V.Y., Zhai, M., Sulloway, H.M., Scholten, J.C., Brown, M.G., Balkwill, D.L. and Daly, M.J. (2008) Protein oxidation: key to bacterial desiccation resistance? ISME J., 2, 393-403.

Fulton, J.D. (1966) Microorganisms of the upper atmosphere. 3. Relationship between altitude and micropopulation, Appl. Microbiol., 14, 237-240.

Galante, D. and Horvath, J.E. (2007) Biological effects of gamma-ray bursts: distances for severe damage on the biota, Int. J. Astrobiol., 6, 19-26.

Gilbert, W. (1986) Origin of life: The RNA world, Nature, $319,618$.

Goossens, O., Vanhavere, F., Leys, N., De Boever, P., O'Sullivan, D., Zhou, D., Spurny, F., Yukihara, E.G., Gaza, R. and McKeever, S.W. (2006) Radiation dosimetry for microbial experiments in the International Space Station using different etched track and luminescent detectors, Radiat. Prot. Dosimetry, 120, 433-437.

Greene, V.W., Pederson, P.D., Lundgren, D.A. and Hagberg, C.A. (1964) Microbiological exploration of stratosphere: Results of six experimental flights, Proceedings of the Atmospheric Biology Conference. National Aeronautics and Space Administration,
Washington, D.C., University of Minnesota, 13-15 April, 1964, pp. 199-211.

Griffin, D.W. (2005) Terrestrial microorganisms at an altitude of $20,000 \mathrm{~m}$ in Earth's atmosphere, Aerobiologia, 20, 135-140.

Griffin, D.W. (2007) Atmospheric movement of microorganisms in clouds of desert dust and implications for human health, Clin. Microbiol. Rev., 20, 459-477.

Griffin, D.W. (2008) Non-spore forming eubacteria isolated at an altitude of $20,000 \mathrm{~m}$ in Earth's atmosphere: extended incubation periods needed for culture-based assays, Aerobiologia, 24, 19-25.

Guérin, B. (1963) Doctor of Pharmacy thesis at Univ. of Paris. Quoted in R.K. Hoffman, 1971, Toxic Gases. In: Hugo, W.B. (Eds.), Inhibition and Destruction of the Microbial Cell. New York, NY: Academic Press, pp. 225-258.

Håland, S., Søraas, F. and Ullaland, S. (1999) Propagation velocities and dimensions of plasmoid structures in the near-Earth magnetotail, Geophys. Res. Lett., 26, 3269-3272.

Hansen, A.A., Herbert, R.A., Mikkelsen, K., Jensen, L.L., Kristoffersen, T., Tiedje, J.M., Lomstein, B.A. and Finster, K.W. (2007) Viability, diversity and composition of the bacterial community in a high Arctic permafrost soil from Spitsbergen, North. Nor. Environ. Microbiol., 9, 2870-2884.

Harris, M.J., Wickramasinghe, N.C., Lloyd, D., Narlikar, J.V., Rajaratnam, P., Turner, M.P., Al-Mufti, S., Wallis, M.K., Ramadurai, S. and Hoyle, F. (2001) The detection of living cells in stratospheric samples. In: Hoover, R.B., Levin, G.V., Paepe, R.R. and Rozanov, A.Y. (Eds.), Proceedings of the SPIE conference. SPIE, Bellingham, WA, pp. 192-198.

Harz, C.O. (1904) Bakteriologische Untersuchungen der freien Atmosphare mittles Luftballons nebst Bemerkungen uber den atmospharischen Staub, Jb. Dtsch. Ltiftsch. Verb., 1904, 293-302.

Horneck, G. (1981) Survival of microorganisms in space: a review, Adv. Space Res., 1, 39-48.

Horneck, G. and Brack, A. (1992) Study of the origin, evolution and distribution of life with emphasis on exobiology experiments in earth orbit, Adv. Space Biol. Med., 2, 229-262.

Horneck, G., Eschweiler, U., Reitz, G., Wehner, J., Willimek, R. and Strauch, K. (1995) Biological responses to space: results of the experiment "Exobiological Unit" of ERA on EURECA I, Adv. Space Res., 16, 105-118.

Horneck, G., Stoffler, D., Eschweiler, U. and Hornemann, U. (2001) Bacterial spores survive simulated meteorite impact, lcarus, 149, 285-290.

Hörz, F., Zolensky, M.E., Bernhard, R.P., See, T.H. and Warren, J.L. (2000) Impact features and projectile residues in aerogel exposedon Mir, Icarus, 147, 559579.

Hoyle, F. and Wickramasinghe, N.C. (1979) Diseases 
from space, Dent, London.

Imshenetsky, A.A., Lysenko, S.V., Kasakov, G.A. and Ramkova, N.V. (1977) Resistance of stratospheric and mesospheric micro-organisms to extreme factors, Life Sci. Space Res., 15, 37-39.

Imshenetsky, A.A., Lysenko, S.V. and Kazakov, G.A. (1978) Upper boundary of the biosphere, Appl. Environ. Microbiol., 35, 1-5.

Imshenetsky, A.A., Lysenko, S.V., Kazakov, G.A. and Ramkova, N.V. (1976) On micro-organisms of the stratosphere, Life Sci. Space Res., 14, 359-362.

Kellogg, C.A. and Griffin, D.W. (2006) Aerobiology and the global transport of desert dust, Trends Ecol. Evol., 21, 638-644.

Kerr, R.A. (2008) Phoenix's water may be gumming up the works, Science, 321, 758.

Kirkby, J. and Carslaw, K.S. (2006) Variations of galactic cosmic rays and the Earth's climate. In: Frisch, P.C. (Eds.), Solar journey: The significance of our galactic environment for the heliosphere and earth. Springer Netherlands, pp. 349.

La Duc, M.T., Kern, R. and Venkateswaran, K. (2004) Microbial monitoring of spacecraft and associated environments, Microb. Ecol., 47, 150-158.

Li, C.S. and Wang, Y.C. (2003) Surface germicidal effects of ozone for microorganisms, AlHA J. (Fairfax, Va), 64, 533-537.

Lundheim, R. (2002) Physiological and ecological significance of biological ice nucleators, Philos. Trans. R. Soc. Lond. B Biol. Sci., 357, 937-943.

Mancinelli, R.L. and Klovstad, M. (2000) Martian soil and UV radiation: microbial viability assessment on spacecraft surfaces, Planet Space Sci., 48, 10931097.

Mastrapa, R.M.E., Glanzberg, H., Head, J.N., Melosh, H.J. and Nicholson, W.L. (2001) Survival of bacteria exposed to extreme acceleration: implications for panspermia, Earth Planet Sci. Lett., 189, 1-8.

Mattimore, V. and Battista, J.R. (1996) Radioresistance of Deinococcus radiodurans: functions necessary to survive ionizing radiation are also necessary to survive prolonged desiccation, J. Bacteriol., 178, 633-637.

Mautner, M. and Matloff, G. (1979) Directed panspermia: a technical evaluation of seeding nearby solar systems, J. Br. Interplanet Soc., 32, 419-422.

McCrory, P. (2004) The big blue revisited, Br. J. Sports Med., 38, 105.

McGovern, J.P., McElhenney, T.R. and Brown, R.M. (1965) Airborne algae and their allergenicity. I. Air sampling and delineation of the problem, Ann. Allergy, 23, 4750.

McLean, R.J.C., Welsh, A.K. and Casasanto, V.A. (2006) Microbial survival in space shuttle crash, Icarus, 181, 323-325.

Melosh, H.J. (1988) The rocky road to panspermia, Nature, 332, 687-688.
Meyer, C., Stöffler, D., Fritz, J., Horneck, G., Möller, R., Cockell, C.S., de Vera, J.P. and Hornemann, U. (2006) Experimental simulation for a launch of viable microorganisms from Mars, Geophys. Res. Abstr., 8, EGU06-A-00554.

Mileikowsky, C., Cucinotta, F.A., Wilson, J.W., Gladman, B., Horneck, G., Lindegren, L., Melosh, J., Rickman, H., Valtonen, M. and Zheng, J.Q. (2000) Natural transfer of viable microbes in space, Icarus, 145, 391-427.

Miller, S.L. (1953) Production of amino acids under possible primitive Earth conditions, Science, 117, 528529.

Miyamoto-Shinohara, Y., Imaizumi, T., Sukenobe, J., Murakami, Y., Kawamura, S. and Komatsu, Y. (2000) Survival rate of microbes after freeze-drying and longterm storage, Cryobiology, 41, 251-255.

Moussa, M., Dumont, F., Perrier-Cornet, J.-M. and Gervais, P. (2008) Cell inactivation and membrane damage after long-term treatments at sub-zero temperature in the supercooled and frozen states, Biotechnol. Bioeng., 101, 1245-1255.

Murray, R.G.E. (1992) The Family Deinococcaceae. In: Balows, A., Trüper, H.G., Dworkin, M., Harder, W. and Schleifer, K.-H. (Eds.), The Prokaryotes: a handbook on the biology of bacteria: ecophysiology, isolation, identification, applications. Springer-Verlag, New York.

Nicholson, W.L. (2004) Ubiquity, longevity, and ecological roles of Bacillus spores. In: Ricca, E., Henriques, A.O. and Cutting, S.M. (Eds.), Bacterial Spore Formers: Probiotics and Emerging Applications. Horizon Scientific Press, Norfolk, UK, pp. 1-15.

Nicholson, W.L., Munakata, N., Horneck, G., Melosh, H.J. and Setlow, P. (2000) Resistance of Bacillus endospores to extreme terrestrial and extraterrestrial environments, Microbiol. Mol. Biol. Rev., 64, 548-572.

Nicholson, W.L. and Schuerger, A.C. (2005) Bacillus subtilis spore survival and expression of germinationinduced bioluminescence after prolonged incubation under simulated Mars atmospheric pressure and composition: implications for planetary protection and lithopanspermia, Astrobiology, 5, 536-544.

Nybakken, L., Solhaug, K.A., Bilger, W. and Gauslaa, Y. (2004) The lichens Xanthoria elegans and Cetraria islandica maintain a high protection against UV-B radiation in Arctic habitats, Oecologia, 140, 211-216.

Oman, L., Robock, A., Stenchikov, G., Schmidt, G.A. and Ruedy, R. (2005) Climatic response to high-latitude volcanic eruptions, J. Geophys. Res., 110, D13103.

Osman, S., Peeters, Z., La Duc, M.T., Mancinelli, R., Ehrenfreund, P. and Venkateswaran, K. (2008) Effect of shadowing on survival of bacteria under conditions simulating the Martian atmosphere and UV radiation, Appl. Environ. Microbiol., 74, 959-970.

Pavlov, A.K., Shelegedin, V.N., Kogan, V.T., Pavlov, A.A., Vdovina, M.A. and Tret'yakov, A.V. (2007) Can microorganisms survive high-temperature heating during the interplanetary transfer by meteorites, Biophysics, 52, 640-644. 
Pósfai, M., Li, J., Anderson, J.R. and Buseck, P.R. (2003) Aerosol bacteria over the Southern Ocean during ACE1, Atmos. Res., 66, 231-240.

Price, P.B. and Sowers, T. (2004) Temperature dependence of metabolic rates for microbial growth, maintenance, and survival, Proc. Natl. Acad. Sci. U. S. A., 101, 4631-4636.

Quint, R.M., Solar, S. and Stan-Lotter, H. (2002) Radiation sensitivity of $N$. pharaonis in comparison with E. coli K12 strains, Radiat. Environ. Biophys., 41, 145-148.

Rabbow, E., Rettberg, P., Baumstark-Khan, C. and Horneck, G. (2003) The SOS-LUX-LAC-FLUOROToxicity-test on the International Space Station (ISS), Adv. Space Res., 31, 1513-1524.

Rainey, F.A., Ray, K., Ferreira, M., Gatz, B.Z., Nobre, M.F., Bagaley, D., Rash, B.A., Park, M.J., Earl, A.M., Shank, N.C., Small, A.M., Henk, M.C., Battista, J.R., Kampfer, P. and da Costa, M.S. (2005) Extensive diversity of ionizing-radiation-resistant bacteria recovered from Sonoran Desert soil and description of nine new species of the genus Deinococcus obtained from a single soil sample, Appl. Environ. Microbiol., 71, 52255235.

Reitz, G., Horneck, G., Facius, R. and Schafer, M. (1995) Results of space experiments, Radiat. Environ. Biophys., 34, 139-144.

Rettberg, P., Eschweiler, U., Strauch, K., Reitz, G., Horneck, G., Wanke, H., Brack, A. and Barbier, B. (2002a) Survival of microorganisms in space protected by meteorite material: results of the experiment 'EXOBIOLOGIE' of the PERSEUS mission, Adv. Space Res., 30, 1539-1545.

Rettberg, P., Rabbow, E., Panitz, C., Reitz, G. and Horneck, G. (2002b) Survivability and protection of bacterial spores in space - the BIOPAN experiment. In: Lacoste, H. (Eds.), First European Workshop on ExoAstrobiology. ESA Publications Division, Graz, Austria, pp. 105-108.

Robock, A. (2002) Pinatubo eruption: The climatic aftermath, Science, 295, 1242-1244.

Rogers, L.A. and Meier, F.C. (1936) The collection of microorganisms above 36,000 feet, Natio. Geographic Soc. Stratosphere Series, 2, 146.

Saffary, R., Nandakumar, R., Spencer, D., Robb, F.T., Davila, J.M., Swartz, M., Ofman, L., Thomas, R.J. and DiRuggiero, J. (2002) Microbial survival of space vacuum and extreme ultraviolet irradiation: strain isolation and analysis during a rocket flight, FEMS Microbiol. Lett., 215, 163-168.

Sancho, L.G., de la Torre, R., Horneck, G., Ascaso, C., de Los Rios, A., Pintado, A., Wierzchos, J. and Schuster, M. (2007) Lichens survive in space: results from the 2005 LICHENS experiment, Astrobiology, 7, 443-454.

Sattler, B., Puxbaum, H. and Psenner, R. (2001) Bacterial growth in supercooled cloud droplets, Geophys. Res. Lett., 28, 239-242.

Schlichting, H.E., Jr. (1969) The importance of airborne algae and protozoa, J. Air Pollut. Control. Assoc., 19, 946-951.

Schmucki, D.A. and Philipona, R. (2002) Ultraviolet radiation in the Alps: the altitude effect, Opt. Eng., 41, 3090-3095.

Seckmeyer, G., Mayer, B., Bernhard, G., Erb, R., Albold, A., Jäger, H. and Stockwell, W.R. (1997) New maximum UV irradiance levels observed in Central Europe, Atmos. Environ., 31, 2971-2976.

Seidel, D.J. (2002) Water Vapor: Distribution and Trends, Encyclopedia of Global Environmental Change. John Wiley \& Sons.

Shivaji, S., Chaturvedi, P., Suresh, K., Reddy, G.S., Dutt, C.B., Wainwright, M., Narlikar, J.V. and Bhargava, P.M. (2006) Bacillus aerius sp. nov., Bacillus aerophilus sp. nov., Bacillus stratosphericus sp. nov. and Bacillus altitudinis sp. nov., isolated from cryogenic tubes used for collecting air samples from high altitudes, Int. J. Syst. Evol. Microbiol., 56, 1465-1473.

Soffen, G.A. (1965) Atmospheric collection at 130,000 feet. Jet Propulsion Laboratory, Document number $65 N 24000$.

Stöffler, D., Horneck, G., Ott, S., Hornemann, U., Cockell, C.S., Moeller, R., Meyer, C., Vera, J.-P.d., Fritz, J. and Artemieva, N.A. (2007) Experimental evidence for the potential impact ejection of viable microorganisms from Mars and Mars-like planets, Icarus, 186, 585-588.

Tanaka, M., Earl, A.M., Howell, H.A., Park, M.J., Eisen, J.A., Peterson, S.N. and Battista, J.R. (2004) Analysis of Deinococcus radiodurans's transcriptional response to ionizing radiation and desiccation reveals novel proteins that contribute to extreme radioresistance, Genetics, 168, 21-33.

Tauscher, C., Schuerger, A.C. and Nicholson, W.L. (2006) Survival and germinability of Bacillus subtilis spores exposed to simulated Mars solar radiation: implications for life detection and planetary protection, Astrobiology, 6, 592-605.

Thomas, D.J., Boling, J., Boston, P.J., Campbell, K.A., McSpadden, T., McWilliams, L. and Todd, P. (2006) Extremophiles for ecopoiesis: desirable traits for and survivability of pioneer martian organisms, Gravit. Space Biol., 19, 91-104.

Titus, T.N., Kieffer, H.H. and Christensen, P.R. (2003) Exposed water ice discovered near the south pole of Mars, Science, 299, 1048-1051.

Tseng, C.-C. and Li, C.-S. (2006) Ozone for Inactivation of aerosolized bacteriophages, Aerosol. Sci. Technol., 683-689.

Wainwright, M., Wickramasinghe, N.C., Narlikar, J.V. and Rajaratnam, P. (2003) Microorganisms cultured from stratospheric air samples obtained at $41 \mathrm{~km}$, FEMS Microbiol. Lett., 218, 161-165.

Wainwright, M., Wickramasinghe, N.C., Narlikar, J.V., Rajaratnam, P. and Perkins, J. (2004) Confirmation of the presence of viable but non-cultureable bacteria in the stratosphere, Int. J. Astrobiol., 3, 13-15.

Warmflash, D., Ciftcioglu, N., Fox, G., McKay, D.S., 
Friedman, L., Betts, B. and Kirschvink, J. (2007) Living interplanetary flight experiment (LIFE): An experiment on the survivalability of microorganisms during interplanetary travel, Workshop on the Exploration of Phobos and Deimos, Moffett Field, California.

Weber, P. and Greenberg, J.M. (1985) Can spores survive in interstellar space? Nature, 316, 403-407.

Wehner, J. and Horneck, G. (1995) Effects of vacuum UV and UVC radiation on dry E. coli plasmid pUC19 I. Inactivation, lac $Z^{-}$mutation induction and strand breaks, J. Photochem. Photobiol. B, 28, 77-85.

Wickramanayake, G.B. and Sproul, O.J. (1988) Ozone concentration and temperature effects on disinfection kinetics, Ozone: Sci. Eng., 10, 123-135.

Wilck, M. and Mann, I. (1996) Radiation pressure forces on "typical" interplanetary dust grains, Planet Space Sci., 44, 493-499.

Willis, M.J., Ahrens, T.J., Bertani, L.E. and Nash, C.Z. (2006) Bugbuster - survivability of living bacteria upon shock compression, Earth Planet Sci. Lett., 247, 185196.

World Health Organization. (2002) Global solar UV index: A practical guide. A joint recommendation of the World Health Organization, World Meteorological Organization, United Nations Environment Programme and International Commission on Non-Ionizing Radiation Protection.

Yamagami, T., Saito, Y., Matsuzaka, Y., Namiki, M., Toriumi, M., Yokota, R., Hirosawa, H. and Matsushima, K. (2004) Development of the highest altitude balloon, Adv. Space Res., 33, 1653-1659.

Yamagishi, A., Yano, H., Okudaira, K., Kobayashi, K., Yokobori, S., Tabata, M. and Kawai, H. (2007) TANPOPO: Astrobiology exposure and micrometeoroid capture experiments, Biol. Sci. Space, 21, 67-75.

Yang, Y., Itahashi, S., Yokobori, S. and Yamagishi, A. (2008a) UV-resistant bacteria isolated from upper troposphere and lower stratosphere, Biol. Sci. Space, 22, 18-25.

Yang, Y., Yokobori, S., Kawaguchi, J., Yamagami, T., lijima, I., Izutsu, N., Fuke, H., Saitoh, Y., Matsuzaka, Y., Namiki, M., Ohta, S., Toriumi, M., Yamada, K., Seo, M. and Yamagishi, A. (2008b) Investigation of cultivable microorganisms in the stratosphere collected by using a balloon in 2005, JAXA Research and Development Report, JAXA-RR-08-001, 35-42.

Yang, Y., Itoh, T., Yokobori, S., Itahashi, S., Shimada, H., Satoh, K., Ohba, H., Narumi, I. and Yamagishi, A. (2009a) Deinococcus aerius sp. nov., isolated from the high atmosphere, Int. J. Syst. Evol. Microbiol., 59, 1862-1866.

Yang, Y., Itoh, T., Yokobori, S., Shimada, H., Itahashi, S., Satoh, K., Ohba, H., Narumi, I. and Yamagishi, A. (2009b) Deinococcus aetherius sp. nov., isolated from the stratosphere, Int. J. Syst. Evol. Microbiol., DOI 10.1099/ijs.0.010876-0.

Yang, Y., Yokobori, S. and Yamagishi, A. (2009c) Bacterial survival in response to desiccation and high humidity at above zero and subzero temperatures, Adv. Space Res., 43, 1285-1290.

Young, S.B. and Setlow, P. (2004) Mechanisms of Bacillus subtilis spore resistance to and killing by aqueous ozone, J. Appl. Microbiol., 96, 1133-1142. 
High-altitude microbes and panspermia

-164 - 